\title{
Technology evaluation of a USA-Mexico health information system for epidemiological surveillance of Mexican migrant workers
}

\author{
Héctor Eduardo Velasco-Mondragón, ${ }^{1}$ Johnson Martin, ${ }^{2}$ \\ and Fernando Chacón-Sosa ${ }^{3}$
}

\begin{abstract}
From 1994 through 1996, federal, state, and nongovernmental organizations in Mexico and in the United States of America developed and piloted a Binational Health Information System for Epidemiological Surveillance of Mexican migrant workers. The system allowed data exchange for epidemiological surveillance between the state of Guanajuato in Mexico and the Commonwealth (state) of Pennsylvania in the United States, for case detection, prevention, and treatment, through shared contact investigation and case management of communicable diseases. The target population consisted of migrant workers traveling between Guanajuato and Pennsylvania to work mainly in the mushroom industry, and their sexual partners in their Mexican communities of origin. Computerized migrant health information modules were set up in Guanajuato and in Pennsylvania. Patient information and epidemiological surveillance data were encrypted and communicated electronically between the modules, using the WONDER communications system of the U.S. Centers for Disease Control and Prevention.

Evaluation of the Guanajuato-Pennsylvania Binational Health Information System showed that major barriers to binational epidemiological surveillance and control are: a) lack of communication binationally; $b$ ) interrupted medical care due to migration; c) inconsistent diagnosis and treatment criteria between the two countries; d) lack of referral clinical records from one country to the other; and e) deficient legal regulations concerning binational clinical data transfer. To our knowledge, this is the first project that has successfully demonstrated the technological feasibility of a binational disease control system linking a state in the interior of one country with a state in the interior of another country, rather than just states in the border region. The project also advanced the understanding of health service organizational issues that facilitate or hinder communication, outreach, disease prevention, and organization of health care services for migrant workers in both Mexico and the United States. Despite the unprecedented success and potential bilateral benefits demonstrated by this project, serious structural and organizational deficits in the public health systems of both countries must be addressed before epidemiological surveillance can be achieved binationally.
\end{abstract}

1 Centro de Investigación en Salud Poblacional, Instituto Nacional de Salud Pública, Cuernavaca, Morelos, México. Address correspondence and reprint requests to: Dr. Eduardo Velasco, Dirección de Epidemiología, Ofna. 345, CISP/INSP, Av. Universidad \#655, Col. Sta. Ma. Ahuacatitlán, Cuernavaca, Morelos, CP 62508, México.

2 Pennsylvania Department of Health, Harrisburg, PA, United States of America.
The geographical mobility of sojourning Mexican migrant workers within the United States of America and between Mexico and the United

3 Secretaría de Salud del Distrito Federal, México, D.F., México.
States poses major barriers to the prevention and control of old and emerging infectious diseases (1) and also to the provision of coordinated health care for migrant populations. International epidemiological surveillance systems, communication networks, in- 
tergovernmental cooperation, and coordination of health systems are all needed to address information gaps which hinder the control and prevention of communicable diseases among migrant workers and their contacts in Mexico and the United States (2).

There is already an intensive exchange of travelers, workers, and goods between Mexico and the United States. With legal and illegal migrant workers, much of the flow is due to economic pressures and unemployment in Mexico (3). In 1996 there were about five million Mexican-born legal residents and 2.4 million unauthorized residents in the United States. During 1995 the number of sojourning migrant workers who traveled from Mexico to the United States to work or look for work was 540 000, with some 433000 going from the United States back to Mexico (4).

Human mobility creates favorable conditions for the movement of communicable diseases and health risks across international borders, and consequently the need for health services from involved countries to address these problems $(5,6)$. Both in the United States and Mexico, migrant workers endure poorer health and greater health risks, as well as more social, economic, and cultural barriers to health care access, than do nonmigrant populations $(7,8)$.

Clinical and field epidemiology personnel are often unable to diagnose and follow up Mexican migrant worker cases due to the workers' traveling between Mexico and the United States or within those two countries. A case detected in one country often reports having contacts in the other country. During the late 1980s and early 1990s the United States experienced a dramatic increase in infectious syphilis (9). This epidemic occurred mostly among heterosexual substance abusers and their sex partners. In Pennsylvania, the outbreak also affected migrant workers, who became infected through contact with prostitutes $(10,11)$. Control of the outbreak was achieved, and screening efforts in migrant camps in 1993-1994 yielded only a small number of syphilis cases and contacts. During this outbreak, some of the migrant cases and contacts were lost to follow-up, and therapy was not given or completed, due to the workers' moving back to Mexico. Efforts by Pennsylvania Department of Health disease control personnel to share data, document clinical outcomes, and identify disease contacts in Mexico were futile and frustrating.

To address these information needs of migrant workers and health care providers, a binational health information system for epidemiological surveillance was designed, implemented, and pilot-tested between the state of Guanajuato in Mexico and the Commonwealth (state) of Pennsylvania in the United States, from 1994 through 1996. Briefly, the objectives of the Guanajuato-Pennsylvania (GUA-PA) Migrant Health Information Pilot Project were to: a) assess the technological feasibility of binational migrant health data exchange; b) collect clinical data on migrant worker disease cases and their contacts for six tracer diseases: tuberculosis, leprosy (Hansen's disease), gonorrhea, syphilis, chlamydia infection, and hepatitis B; c) assess the compatibility of the Mexico and United States epidemiological surveillance systems; and d) identify security and confidentiality issues in the sharing of clinical and epidemiological information between the two countries.

This paper presents a brief description and technology evaluation of the GUA-PA pilot project. The background and preliminary design of this project have been published elsewhere (12).

\section{MATERIAL AND METHODS}

The GUA-PA Pilot Project was in place from March 1994 to May 1995. The target population were nearly 2500 migrant workers who travel between Guanajuato and Pennsylvania and who work mainly in the mushroom industry. This is a relatively steady migrant flow, composed largely of males. A detailed study of the health needs and access to health care for this specific population was conducted in 1993 by one of the authors (13). Eligible cases to participate in GUA-PA included any suspected or confirmed case with one of the six tracer diseases and his contacts, where the case required sharing clinical and epidemiological data across the border to complete disease investigation and where that person gave written informed consent.

This was a demonstration pilot project to assess the feasibility of binational migrant health data exchange for epidemiological surveillance of migrant populations. The evaluation framework of the project is based on the protocol for the evaluation of epidemiological surveillance systems proposed by the World Health Organization (14). Evaluation results are presented in terms of structure, process, and outcomes. The outcomes subsection describes five barriers to coordinated binational epidemiological surveillance and disease prevention and control. In addition, we present the evaluation of GUA-PA through the attributes of an epidemiological surveillance system.

\section{RESULTS}

\section{Structure}

The health information system design best meeting GUA-PA's information needs was a modular one (15). Its structure is shown in Figure 1.

Migrant Health Information Modules were implemented at the head office of the Ministry of Health of Guanajuato, which is in the city of Guanajuato, and also at the head office of the Pennsylvania Department of Health, in Harrisburg, Pennsylvania. Personnel from the U.S. Centers for Disease Control and Prevention (CDC) assigned to the Pennsylvania Department of Health Sexually Transmitted Diseases Control Program designed the paper and electronic format for data exchange. Called MUST, for Mexico-US Transfer, the format included demographic, clinical, laboratory, and case definition data for the six tracer diseases, as well as open text fields. MUST formats included range 
FIGURE 1. Modular design of the GUA-PA Migrant Health Information System

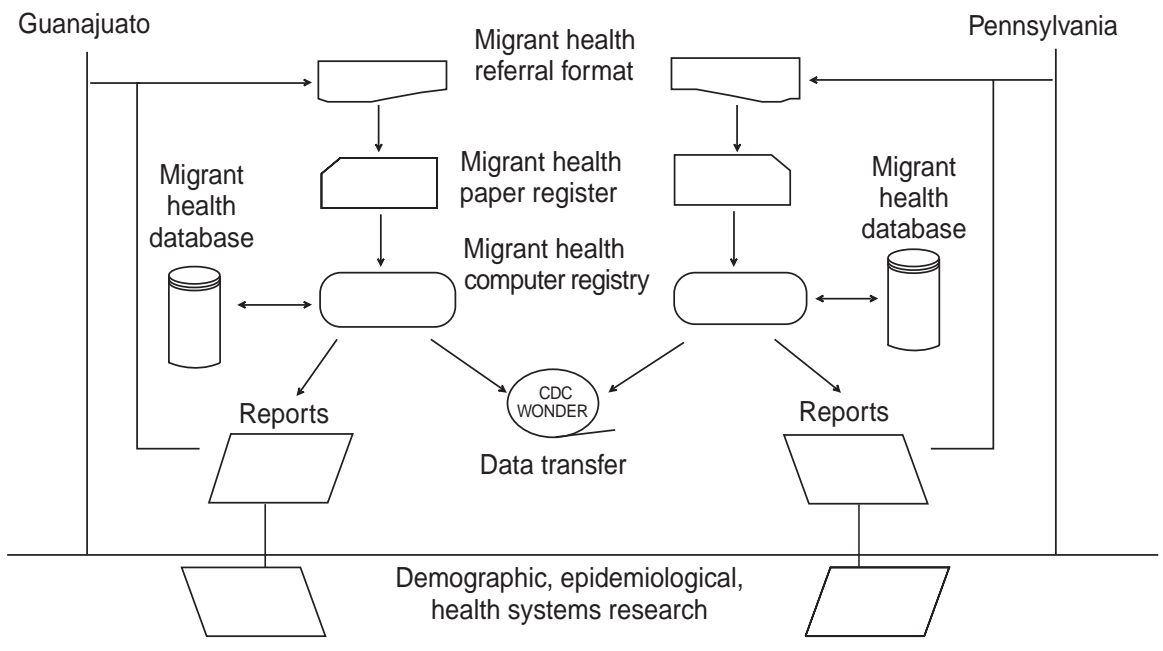

and logical checks to assure data quality. Identification data consisted of the Mexican taxpayer code (Registro Federal de Causantes, or RFC), which is a unique identifier made up of an individual's name initials and date of birth. MUST electronic forms were viewable in Spanish in Guanajuato and in English in Pennsylvania. Case definitions followed the International Classification of Diseases-10th Revision (ICD-10th) (16).

The computerized system required only basic hardware: a computer with a 386 or better processor chip, at least four megabytes of random access memory (RAM), a minimum of five megabytes of available hard disk space, and a modem. Also required were special database software (the electronic version of the paper MUST format), which performed data encryption and decryption, and CDC's WONDER communications software (U.S. Centers for Disease Control and Prevention, Atlanta, GA), which enables authorized users (mostly United States public health workers) to e-mail messages and exchange electronic files through CDC's WONDER Internet web site (http://wonder.cdc.gov). Data files were transferred between GUA-PA modules by modem through a toll-free, dedicated phone line set up by the CDC. The structure of the GUAPA system allowed efficient electronic transfer of health data, with no breaches of security or confidentiality. Data flowed smoothly into each country's epidemiological surveillance data registries. Once data were exchanged, personnel from the Pennsylvania Department of Health, from migrant health clinics, and from the Guanajuato Ministry of Health field epidemiology unit supported the detection, track-down, and follow-up of cases and contacts.

\section{Process}

Cases were recruited by passive detection through epidemiological surveillance systems in place in Guanajuato and in Pennsylvania, and through two other methods, outreach screening for sexually transmitted diseases (STDs) and tuberculosis (TB) in Pennsylvania migrant camps and a survey conducted in migrant sender communities of Guanajuato.

STD screening was carried out among Mexican migrant farmworkers in Pennsylvania, to detect syphilis, gonorrhea, and chlamydial infection. For the TB screening in Pennsylvania, skin testing was conducted, and skintest positives received a chest $X$ ray and were started on anti-TB prophylaxis or treatment. During the course of the pilot study, seven individuals who had begun TB prophylaxis in Pennsylvania returned to Mexico. They received uninterrupted treatment while at home in Mexico and then completed their treatment after returning to Pennsylvania.

The survey in Mexico actively sought STD cases in the migrant sender communities of Guanajuato, among sexual partners (mostly wives) of migrant workers. ${ }^{4}$

Completed MUST forms were given to field personnel to locate cases and contacts in Guanajuato. Track-down and follow-up of a given case or contact required time- and labor-intensive work by a team composed of project researchers, field epidemiologists, and social service personnel. Personnel from the services, laboratory, clinical, and field epidemiology units of both the Pennsylvania and Guanajuato Departments of Health participated in the disease control activities.

\section{Outcomes}

In this project, study researchers were able to exchange data between Pennsylvania and Guanajuato on about 20 disease cases and their contacts. However, tracing of cases and contacts was done only for the migrant flow from the United States to Mexico. In addition, we analyzed information on a similar number of cases whose data were not binationally exchanged. Analysis of cases whose data were not binationally exchanged through GUAPA allowed us to detect several problems outside GUA-PA. Also, since GUA-PA was developed in a context of intervention to improve access to health care for migrant workers both in Guanajuato and in Pennsylvania, we carried out health care referral activities and helped migrant workers to obtain health care services in both countries, which gave us additional information on communication barriers.

\footnotetext{
4 Velasco-Mondragón HE, Cruz-Valdés A, CruzOlivares JA, Martin J. Sexually transmitted diseases among sexual partners of Mexican migrant workers [unpublished paper]. Instituto Nacional de Salud Pública. 1996.
} 
GUA-PA case studies analyzed during the study period showed five main barriers to coordinated disease prevention and control activities.

The first of the barriers evidenced by GUA-PA is the lack of binational communication between epidemiological surveillance systems at the state level. Unfortunately, in GUA-PA, virtually all of the requests to track down cases and contacts originated from the United States, with few or none from Mexico. In addition to cases and contacts of communicable diseases, GUAPA showed the need to communicate clinical data for noncommunicable conditions and other health risks. Outside GUA-PA, efforts to communicate migrant health data binationally for case and contact tracing are commonly futile. There is a lack of knowledge about whom and how to contact the other country's epidemiological surveillance and health care personnel at the local level.

Among other things, GUA-PA established communication between health services, which allowed several important disease detection and control activities. One such activity was the identification of particular risks of developing "mushroom worker's lung," a form of rare but potentially fatal hypersensitivity pneumonitis. Unconfirmed verbal accounts reported Mexican migrant workers having to quit working in mushroom camps due to acute respiratory conditions associated with mushroom picking. This information was communicated to Guanajuato and to Pennsylvania local health services in migrant communities to increase their awareness of this condition and increase their likelihood of detecting it.

In another GUA-PA communications linkage, epidemiological surveillance personnel from Guanajuato reported that the number of leprosy cases prevalent in just that state was nearly equal to the number for the entire United States (Dr. Yañez-Velasco, personal communication, February 1995). Some of these leprosy cases enter the Mexico-United States migrant streams, a fact that Pennsylvania
State Health Department authorities were unaware of prior to GUA-PA. As a result, the United States Hansen's Disease Center in Carville, Louisiana, trained migrant health care providers in Pennsylvania's Chester County in leprosy detection and control, which resulted in an increase in the number of cases identified among migrant workers (J. Martin, personal communication, January 1997)

In a third GUA-PA communication linkage, Guanajuato Department of Health officials reported that hepatitis B was a major health concern in that Mexican state; as a result, immunization for hepatitis is now provided to migrant farm workers in Pennsylvania as part of that state's STD control program.

GUA-PA showed that a second barrier to binational coordinated disease prevention and control activities is interrupted medical care. GUA-PA study subjects with a communicable and/or noncommunicable disease reported having to stop taking their medication due to migration; typical cases were patients with tuberculosis, leprosy, high blood pressure, diabetes, or epilepsy. Some of these patients were given or bought enough medication to last through the several months of stay in either country and some were able to carry it surreptitiously across the border. However, they reported that, if detected by United States customs officers at the United States-Mexico border, their medication is usually seized, even if a Mexican doctor's prescription is presented.

During follow-up of GUA-PA study subjects, we identified that inconsistent diagnosis and treatment criteria between Mexico and the United States health care services are another barrier to coordinated disease prevention and control activities. GUA-PA patients diagnosed with a condition by health care providers in one country had their diagnosis ruled out or not recognized in the other country. Even in the few instances in which patients did carry a clinical referral note obtained in one country, that diagnosis had to be confirmed by the health services in the second country. This resulted in multiple diagnostic testing, inconsistent drug therapies, increased costs, and inconvenience for patients. For example, in Mexico, GUA-PA participant patients with tuberculosis, who could not afford to buy medication, were not eligible for state-run tuberculosis-control programs, which provide free drug therapy, unless they tested positive for tuberculosis at the local laboratory in Guanajuato. One patient had repeated positive tuberculosis results from United States health services, but tested negative in Guanajuato and was not eligible to enter the tuberculosis control program. He had run out of tuberculosis medication and his treatment was interrupted. A similar case was that of a woman positive for HIV in a United States lab and in a Guanajuato private lab, but negative in Guanajuato's Ministry of Health lab. Similarly, Mexican patients who traveled to the United States were unable to buy medication prescribed in Mexico, and their diagnoses were ignored.

A fourth barrier to coordinated disease prevention and control activities evidenced by GUA-PA is the lack of binational referral clinical records or notes. For GUA-PA study subjects, the MUST form served this purpose well. Patients whose data were not exchanged through GUA-PA rarely were given clinical notes and lab results to carry with them across the border. Even if they were, language barriers and clinical disagreements limited their usefulness. A related problem we found was the lack of documentation of occupational health problems and work-related injuries that occurred in the United States and were treated in Mexico, where the worker was entitled to file an economic claim through the workers' compensation system in the United States, which covers the medical expenses of employees injured on the job. Patients were willing to forgo such claims due to the difficulty of having medical care institutions or practitioners issue clinical notes or release clinical information.

A fifth barrier to coordinated disease prevention and control activities identified through GUA-PA was the 
deficiency of legal regulations regarding binational clinical data transfer. No clear regulations existed, in either Mexico or the United States, on assurance of confidentiality, compulsory disclosure of patient's identifiers, ownership of clinical data, limitations of purposes of data, destruction of data, and liability for unauthorized utilization of data. Obviously, undocumented migrant workers in the United States may be more affected by disclosure of clinical and identification data than documented workers, since the migrant workers could face deportation due to both their undocumented and disease status.

\section{Epidemiological surveillance system attributes}

GUA-PA is evaluated below in line with eight attributes for the evaluation of epidemiological surveillance systems proposed by the World Health Organization (17): representativeness, simplicity, flexibility, timeliness, acceptability, sensitivity, positive predictive value, and affordability. Each attribute is presented in terms of GUA-PA's performance and further requirements for improvement and general application.

Representativeness. Even though some of our study subjects had medical insurance through the Mexican Institute of Social Security (MISS) or other public health care institutions in Mexico, many reported utilizing private health care providers. In Mexico, there were indications that some of these providers were not complying with compulsory reporting of notifiable diseases. Underreporting of migrant disease cases would compromise GUAPA's representativeness. In addition, both in Mexico and the United States, precise estimates of the occurrence of disease among Mexican migrant workers are inaccurate, since undocumented and legal migrant workers frequently do not demand or do not utilize mainstream health care services in the
United States or Mexico and thus escape epidemiological surveillance systems in the two countries (13). Among GUA-PA patients and migrant workers in general, there is frequent use of traditional healers in Mexico and selfmedication in both countries (such as some GUA-PA cases who treated their gonorrhea in the United States using penicillin they had managed to smuggle in from Mexico), thus escaping detection by epidemiological surveillance systems. Binational epidemiological surveillance systems such as GUA-PA would help generate better prevalence and incidence estimates of notifiable diseases and their distribution among migrant populations, as well as improving those estimates for the population at large in their sender and receiving communities.

Simplicity and flexibility. GUA-PA's modular design ensured the simplicity and flexibility of binational epidemiological surveillance and showed great potential for expansion within and between countries. Migrant sender and recipient states could link up with the system one by one. In GUA-PA, further training of epidemiological surveillance field personnel and migrant health care providers was necessary to collect data using the paper MUST forms. Forms were completely filled out and information was sufficient to identify cases and contacts; however, both in Mexico and the United States, migrant workers often resided or worked in rural areas with imprecise addresses that were time-consuming to locate.

Our experience with GUA-PA leads us to believe that, using the MUST paper form, any health care provider could be a source of data and could recruit migrant disease cases or contacts into the system. More diseases could be included, as well as other types of binationally mobile populations, such as tourists and students. Data need not be transmitted through the WONDER system, since MUST paper forms could be faxed directly, or electronic files divested of identifying information could be communicated directly by modem between each countries' epidemiological surveillance systems. Finally, migrant health databases generated by systems like GUA-PA could be linked with other computer records, using Mexico's RFC taxpayer identification system.

Timeliness. In GUA-PA, timeliness of the migrant health epidemiological surveillance system was a major challenge, since tracking of communicable diseases needed to be prompt and because of the high geographical mobility of migrant workers within and between Mexico and the United States. After completed forms were received by either country, it was necessary to devote specific personnel, time, and resources to case and contact finding and follow-up. Even though GUA-PA allowed unprecedented availability of data for epidemiological surveillance systems and front-line health care providers in Mexico and the United States, it was difficult to utilize because the contact tracing and follow-up required extensive time and resources.

Acceptability. Both in Mexico and in the United States, acceptability of GUA-PA by health care personnel was limited, since case finding and followup was considered an additional unpaid workload and time burden on field personnel. Also, migrant health care providers expressed concerns about confidentiality and security of data. Regarding confidentiality, cases were reluctant to provide information on contacts or to authorize communication with their contacts. Contacts in Mexico were approached and offered free preventive health services, including those relating to the tracer disease. A migrant health clinic in Pennsylvania heard about a rumor regarding the alleged detection and public exposure of AIDS cases among migrant workers in their communities of origin in Guanajuato. This rumor was investigated and found to be untrue; however, it signaled a major threat that could eas- 
ily deter migrant workers and their families from participating in binational epidemiological surveillance.

Sensitivity. In GUA-PA, sensitivity depended largely on the compatibility of clinical and diagnostic criteria between Mexico and the United States and on the quality of collected data. Since a significant number of migrant workers are not covered by the health systems in Mexico and the United States, the proportion of disease cases detected by a system like GUA-PA may be significantly lower than for nonmigrant populations. However, since severity of disease among GUAPA cases was related to case detection, any migrant-worker cases that were detected and included were likely to be true cases, and this improved its sensitivity. GUA-PA has a great potential for detecting epidemics, particularly through sentinel surveillance, which could be carried out for endemic diseases in migrant sender and recipient localities. For example, Lyme disease occurs in rural areas of Pennsylvania and could be carried to Guanajuato. Detection of one case of Lyme disease in Guanajuato could signal the need for preventive measures. Similarly, several cases of leprosy from Guanajuato that enter the United States migrant streams every year could be detected.

Positive predictive value. Positive predictive value (PPV) is the proportion of persons identified as cases who, upon testing and examination, actually have a particular disease. A second indicator of PPV is the number of epidemics the surveillance system finds among migrant populations and that really are epidemics. Diseased migrant workers who are identified as cases by epidemiological surveillance systems in Mexico and the United States are likely to be true cases that have been detected despite several obstacles. Assessment of the second, epidemic indicator requires implementing the surveillance system and accruing a number of detected epidemics.
Affordability. Even though GUA-PA was designed to integrate with surveillance systems in place in Mexico and the United States, additional costs included the personnel needed to implement and operate the migrant health modules (at least one committed community health care worker and a database manager), tests performed on apparent cases and contacts who come out negative, expenses for transmitting information via e-mail and for additional paperwork, and transportation costs of field investigation personnel for case and contact track-down and follow-up. These costs may be offset by not having to perform duplicate testing and by avoiding haphazard treatment. However, incompatibility of clinical criteria between Mexico and the United States would make it necessary to perform duplicate testing.

\section{DISCUSSION}

GUA-PA allowed direct communication and contact between the migrant health care providers and epidemiological surveillance systems of Mexican migrant sender communities and United States migrant recipient communities.

Clinical data exchange within GUAPA raised several concerns regarding confidentiality of data, particularly in the face of deficient legislation. However, current electronic medical record technology offers the same or greater security and confidentiality of data as do paper records (18-20) and should suffice to protect data transfer between Mexico and the United States. Also, international regulations of electronic medical records (21) and standardization of laboratory data are being developed (22).

Communication and information technology is now available for international public health surveillance systems, epidemic control, and medical care. Telemedicine and health geographic information systems offer powerful tools and methods to assess the health conditions and needs of mo- bile populations. However, GUA-PA showed that these technologies are ineffectual without concomitant international organizational development of epidemiological surveillance systems, training of epidemiology field personnel, and standardization of clinical and laboratory criteria.

Migrant health data are scarce; systems like GUA-PA would help generate migrant health indicators that would improve the morbidity and mortality estimates of migrant populations and would help to identify international routes of disease transmission. Only after accurate estimates are available will it be possible to implement disease prevention and control interventions and to evaluate their impact. As for binational medical care, systems like GUA-PA could also exchange clinical data on noncommunicable conditions and work-related injuries.

A review of international epidemiological surveillance systems shows that the need to share epidemiological and clinical information between health care services in Mexico and the United States is being addressed partially by collaborative projects focused on the United States-Mexico border states. However, current border health initiatives neglect migrant populations moving back and forth between the interior states of the two countries.

Attempts have been made by the Mexican Institute of Social Security (MISS) to sell to migrant workers in the United States medical insurance for themselves and for their families. MISS coverage is mandatory in Mexico for all salaried workers not employed by the Mexican Government. However, MISS services can only be rendered in Mexico and thus this insurance is unsuited for the needs of this migrant population (13). In addition, MISS has no collaborative arrangements with health services in the United States to exchange migrant health data. For example, previous attempts by the authors to obtain and exchange medical records needed to document occupational injuries for workers' compensation were futile. Further, geographic information sys- 
tems implemented by state governments in Mexico (23) and MISS reform initiatives funded with loans from the World Bank to extend coverage to selfemployed and informal sector workers (24) overlook the health needs of Mexican migrant workers.

Three key measures that would greatly advance binational migrant health information systems and epidemiological surveillance in Mexico and the United States are: a) developing a network of migrant health care providers in migrant sender and receiving communities in both countries, b) developing a unique migrant health data exchange form or the inclusion of migrant health in standard disease notification forms, and c) characterizing migration patterns and health status indicators of specific migrant populations and exchanging those data between sender and receiving communities of Mexico and the United States.

We hope that the findings and recommendations generated by this study will contribute to the development of a permanent, institutionalized binational migrant-worker health information system between Mexico and the United States, as well as greater binational cooperation in health care and epidemiological surveillance for migrant populations.

Acknowledgments. The authors would like to acknowledge the support and participation of the following institutions: Secretaría de Salud del Estado de Guanajuato; Pennsylvania Department of Health; Instituto Nacional de Salud Pública, Escuela de Salud Pública de México; Migrant Clinicians Network; the U.S. Office of Minority Health; the U.S. Centers for Disease Control and Prevention, and Christopher Newport University.

\section{REFERENCES}

1. Berlinguer $G$. The interchange of disease and health between the Old and New Worlds. Am J Public Health 1992;82(10):1407-1413.

2. Henderson DA. Surveillance systems and intergovernmental cooperation. In: Morse SS, ed. Emerging viruses. 1st ed. New York, Oxford: Oxford University Press; 1993. pp. 283-290.

3. Massey DS, Arango J, Hugo G, Kouaouci A, Pellegrino A, Taylor JE. Theories of international migration: a review and appraisal. Pop Dev Rev 1993;19:431-466.

4. Binational Study on Migration. Migration between Mexico \& the United States. Binational study. A report of the Binational Study on Migration. Report. Mexico, United States: Binational Study on Migration; 1998.

5. Gellert GA. International migration and control of communicable diseases. Soc Sci Med 1993;37(12):1489-1499.

6. Morse SS. Global microbial traffic and the interchange of disease. Am J Public Health 1992; 82(10):1326-1327.

7. Farmer P. Social inequalities and emerging infectious diseases. Emerg Infect Dis 1996;2(4): 259-269.

8. Rust GS. Health status of migrant farmworkers: a literature review and commentary. Am J Public Health 1990;80(10):1213-1217.

9. Williams LA, Klausner JD, Whittington WLH, Handsfield HH, Celum C, Holmes KK. Elimination and reintroduction of primary and secondary syphilis. Am J Public Health 1999; 89(7):1093-1100

10. Pennsylvania Department of Health. Infectious syphilis in Chester, PA. Pennsylvania Health Reporter 1989;10(2):1-2.
11. Much D, Martin J. Relationship between substance abuse and sexually transmitted diseases. Journal of the Pennsylvania Academy of Science 1995;68(1):1-4.

12. Velasco Mondragón HE, Stevenson-Perez $\mathrm{H}$, Martin J. Binational health care for migrants: the Health Data Exchange Pilot Project and the Binational Data Transfer System. In: Flores JL, ed. Children of la frontera: binational efforts to serve migrant and immigrant students. Charleston, WV: ERIC Clearinghouse on Rural Education and Small Schools; 1996. pp. 183-201.

13. Velasco-Mondragón HE. Accesibilidad a los servicios de salud para trabajadores migrantes en Pensilvania, EUA. [Master's thesis]. Cuernavaca, Morelos, México: Instituto Nacional de Salud Pública; 1994.

14. World Health Organization. Protocol for the evaluation of epidemiological surveillance systems. Geneva: WHO; 1997. (WHO publication WHO/EMC/DIS/97.2).

15. Austin $\mathrm{CHJ}$, William JH. Information systems for health services administration. 3rd ed. Ann Arbor, Michigan: Health Administration Press; 1988.

16. Organización Panamericana de la Salud. Clasificación estadística internacional de enfermedades y problemas relacionados con la salud. Décima revisión. Washington, D.C.: Organización Panamericana de la Salud, 1995.

17. Klaucke DN. Evaluating public health surveillance systems. In: Halperin W, Baker E, eds. Public health surveillance. New York: Van Nostrand Reinhold; 1992. pp. 26-41.
18. Espinosa AL. Availability of health data: requirements and solutions. Int J Med Inf 1998; 49(1):97-104.

19. Barber B. Patient data and security: an overview. Int J Med Inf 1998;49(1):19-30.

20. Quantin C, Bouzelat H, Allaert FA, Benhamiche AM, Faivre J, Dusserre L. How to ensure data security of an epidemiological follow-up: quality assessment of an anonymous record linkage procedure. Int J Med Inf 1998; 49(1):117-122.

21. Fidler DP. Globalization, international law, and emerging infectious diseases. Emerg Infect Dis 1996;2:(2)77-84.

22. Elevitch FR, Boroviczeny KG. Transfer data. A proposed international standard for interlaboratory information exchange. Arch Pathol Lab Med 1985;109:496-498.

23. Gobierno del Estado de Guanajuato. Sistema de información para la planeación. [Internet site] http://sip. guanajuato.gob.mx/. Accessed on 1 January 1998.

24. World Bank. IMSS health care reform. [Internet site] http://www.worldbank.org/html/ extdr/extme/1866.htm. Accessed on $6 \mathrm{Au}$ gust 1998.

Manuscript received on 23 March 1999. Revised version accepted for publication on 12 December 1999. 
RESUMEN De 1994 a 1996, algunas organizaciones federales, estatales y no gubernamentales en México y los Estados Unidos de América han creado y puesto en marcha un Sistema de Información de Salud Binacional para la Vigilancia Epidemiológica de trabajadores itinerantes mexicanos. El sistema permitió el intercambio de información epidemiológica entre el estado de Guanajuato en México y el estado de Pensilvania en los Estados Unidos, en lo referente a la detección, prevención y tratamiento de casos, mediante la investigación de contactos en común y el manejo de personas con enfermedades transmisibles. La población destinataria se compuso de trabajadores itinerantes que viajaban entre Guanajuato y Pensilvania para trabajar principalmente en la industria de los hongos, y de sus compañeras sexuales en las comunidades mexicanas de donde provenían. Se montaron módulos de información sanitaria computadorizados para los itinerantes en Guanajuato y Pensilvania. Los datos sobre los pacientes y la vigilancia epidemiológica se codificaban y enviaban por la vía electrónica de un módulo a otro mediante el sistema de comunicaciones WONDER, perteneciente a los Centros para el Control y la Prevención de Enfermedades de los Estados Unidos.

La evaluación del Sistema de Información de Salud Binacional entre Guanajuato y Pensilvania reveló que las barreras que más obstaculizan la vigilancia y el control epidemiológicos en el ámbito binacional son las siguientes: a) la falta de comunicación entre los dos países; b) la interrupción de la atención médica con motivo de la migración; c) la poca concordancia entre los criterios de diagnóstico y tratamiento de ambos países; d) la falta de expedientes clínicos para remitir al paciente de un país a otro, y e) la deficiencia de los reglamentos legales en torno a la transferencia de información clínica en el nivel binacional. Este es, a nuestro parecer, el primer proyecto en demostrar la factibilidad tecnológica de un sistema binacional para el control de enfermedades que conecte un estado dentro de un país con otro en un país diferente, y no simplemente dos estados en la zona limítrofe. El proyecto también ha permitido conocer más a fondo algunos aspectos de la organización de los servicios de salud que facilitan u obstaculizan la comunicación, las actividades de promoción social, la prevención de enfermedades y la organización de los servicios de salud para trabajadores itinerantes, tanto en México como en los Estados Unidos. Pese al éxito inaudito de este proyecto y a los beneficios bilaterales que ha mostrado poder aportar, hay deficiencias graves en la estructura y organización de los sistemas de salud pública de ambos países que deben ser examinadas antes de que se logre una vigilancia epidemiológica de carácter binacional. 